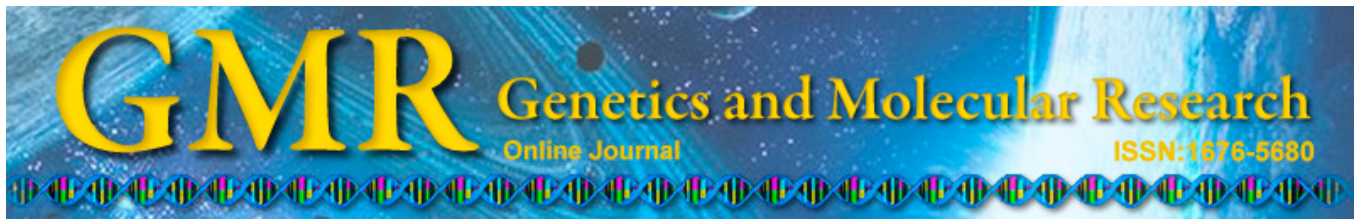

\title{
Associations between the SRD5A2 gene V89L and TA repeat polymorphisms and breast cancer risk: a meta-analysis
}

\author{
D. Zhang1, Q. Li' ${ }^{2}$ H.-C. Qu ${ }^{3}$, T. Yü and Y.-R. Liu ${ }^{1}$ \\ ${ }^{1}$ College of Basic Medical Science, China Medical University, \\ Shenyang, Liaoning, China \\ ${ }^{2}$ Laboratory Center, The Fourth Affiliated Hospital of China Medical University, \\ Shenyang, Liaoning, China \\ ${ }^{3}$ Department of Urological Surgery, \\ The Fourth Affiliated Hospital of China Medical University, Shenyang, \\ Liaoning, China \\ Corresponding author: Y.-R. Liu \\ E-mail: 13386861962@163.com
}

Genet. Mol. Res. 14 (3): 9004-9012 (2015)

Received January 8, 2015

Accepted May 8, 2015

Published August 7, 2015

DOI http://dx.doi.org/10.4238/2015.August.7.9

\begin{abstract}
The 5 $\alpha$-reductase type 2 (SRD5A2) gene plays a significant role in the development of breast cancer. The V89L and TA repeat polymorphisms of the $S R D 5 A 2$ gene have been considered as risk factors for breast cancer. However, the results have been inconsistent. To resolve this conflict, we performed a meta-analysis of studies with V89L (1144 patients and 808 controls) and with TA repeat genotyping (1952 cases and 1008 controls). The associations were evaluated by calculating odds ratios (ORs) and 95\% confidence intervals (CIs). The result showed that there was no relationship between the V89L polymorphism of the $S R D 5 A 2$ gene (V/V versus $\mathrm{V} / \mathrm{L}+\mathrm{L} / \mathrm{L}$ genotypes) and breast cancer susceptibility $(\mathrm{OR}=1.21 ; 95 \% \mathrm{CI}=0.99-1.47 ; \mathrm{P}=$ 0.28). In addition, there was no difference between patients with breast cancer and healthy people in the distributions of the L allele $(\mathrm{OR}=1.06$;
\end{abstract}


$95 \% \mathrm{CI}=0.75-1.49 ; \mathrm{P}=0.003)$. Similarly, no significant association between the $S R D A 5 A 2$ TA repeat polymorphism and breast cancer risk was discovered. The comparison of (TA $)_{0} /(\mathrm{TA})_{0}$ versus $(\mathrm{TA})_{0} /(\mathrm{TA})_{9}+$ $(\mathrm{TA})_{9} /(\mathrm{TA})_{9}$ genotypes found no difference in the risk of breast cancer $(\mathrm{OR}=0.91 ; 95 \% \mathrm{CI}=0.66-1.25 ; \mathrm{P}=0.05)$. The $\mathrm{OR}$ for the $(\mathrm{TA})_{0}$ versus (TA) allele was $0.89(95 \% \mathrm{CI}=0.67-1.19)$. In conclusion, the V89L and TA repeat polymorphisms of SRD5A2 gene were found to have no significant associations with breast cancer risk.

Key words: SRD5A2 genes; V89L polymorphism; Breast cancer; TA repeat polymorphism; Meta-analysis

\section{INTRODUCTION}

Worldwide, breast cancer has become one of the most common malignant tumors and is the leading cause of cancer death among women (Althuis et al., 2005). The incidence rate of breast cancer has increased quickly, especially in developed countries (Yip and Taib, 2014). The genesis of breast cancer is a multi-factorial and complex process. Although little is known about the etiology of breast cancer, evidence has shown that estrogenic hormones play a significant role in its causation and progression (Reding et al., 2009; Leclercq and Jacquot, 2014). In addition, the genes involved in the estrogen metabolic pathway and polymorphic variants in the relevant enzymes have been associated with breast cancer as well (Lewis et al., 2004; Tian et al., 2014). Among these genes, expression of the 5 $\alpha$-reductase type 2 gene (SRD5A2) has been found to be altered in breast cancer, which might correspond to the risk of developing breast cancer (Tian et al., 2014).

The $5 \alpha$-reductase enzyme is responsible for the conversion of progesterone $(\mathrm{P})$ to $5 \alpha$-pregnane $(5 \alpha \mathrm{P})$, which is one of the most important P-metabolizing enzymes in human breast tissues (Wiebe, 2006). It has been reported that the production of $5 \alpha \mathrm{P}$ was altered between normal breast and breast cancer tissues. Therefore, $5 \alpha$-reductase might directly affect the origin of breast cancer. The SRD5A2 gene encodes a $5 \alpha$-reductase and is located on human chromosome $2 \mathrm{p} 23$. According to the dbSNP database, SRD5A2 is highly polymorphic, and include two common valine to leucine missense substitutions at codon89 (V89L) and a polymorphic dinucleotide repeat (TA)n in the 3'-untranslated region. To clarify whether the SRD5A2 V89L and TA repeat polymorphisms are associated with breast cancer risk, we carried out a comprehensive meta-analysis.

\section{MATERIAL AND METHODS}

\section{Search strategy}

A comprehensive literature search of the PubMed, Embase, Medline, Cochrane Library, Web of Science, and Chinese BioMedical databases was carried to identify relevant studies published as recently as July 10,2014. We developed a search strategy using the following key words: "SRD5A2", "V89L" or "rs523349", “(TA)n” or "TA repeat", "polymorphism" and "breast cancer" (Text Word). An extensive searching from the reference lists of the selected articles was performed, and the relevant studies were reviewed to identify other eligible studies manually. 


\section{Inclusion and exclusion criteria}

To be eligible for inclusion in the meta-analysis, studies were required to satisfy the following criteria: a) the study examined the associations between the SRD5A2 V89L and/or TA repeat polymorphisms and the risk of breast cancer; b) the article was a case-control study; c) the patients had a diagnosis of a malignant tumor confirmed by pathological examination of a surgical specimen; d) the study provided original data and continuous variables; and e) the full text of the published study could be accessed. Additionally, if studies represented the same or overlapping data published in various journals or in different years, we selected the most recent publications with the largest total number of subjects. Studies were excluded if they reported incomplete, or lacked the necessary information for this meta-analysis, or if they were abstracts, comments, reviews, letters, or editorial articles.

\section{Data extraction}

Using a standardized form, two reviewers (D. Zhang and H.-C. Qu) performed the search and evaluated the eligibility of the studies and extracted the necessary information. The following information was sought from each report: first author, year of publication, study design, number of controls and of patients, source of controls, genotyping method, and V89L and TA repeat polymorphism genotype data. Any discrepancy between the two reviewers was resolved by discussion and consultation with a third reviewer (Y.-R. Liu) and an ultimate decision was reached on all of the items.

\section{Quality assessment of the included studies}

Among the studies included in this analysis, all were case-control group studies. Accordingly, we estimated their methodological quality based on the Newcastle-Ottawa Scale (NOS). A star system of the NOS was used for evaluation, with the quality level of each identified study ranging from 0 to 9 stars. A score $\geq 6$ stars was considered to be high quality (Sang et al., 2013); the scores of our included studies were $\geq 6$ stars. Two reviewers (Q. Li and T. Yu) independently performed the study assessments according to the above quality score system. Differences were resolved by discussion among the authors.

\section{Statistical analysis}

Odds ratios (ORs) and 95\% confidence intervals (CIs) were calculated to assess the strength of the association between the V89L or TA repeat polymorphism and breast cancer risk using the Review Manager Version 5.3 software (provided by Cochrane Collaboration; http://ims.cochrane.org/revman/download). For V89L, we analyzed the contrast of L versus $\mathrm{V}$ alleles in patients with breast cancer and normal controls. In addition, we examined the contrast of genotypes $\mathrm{L} / \mathrm{L}$ versus $(\mathrm{V} / \mathrm{L}+\mathrm{V} / \mathrm{V})$. These contrasts correspond to the recessive and dominant effect models, respectively. Similar contrasts were performed for the TA repeat polymorphism, wherein we contrasted the longer $\mathrm{TA}_{(9)}$ allele versus the short $\mathrm{TA}_{(0)}$ allele and the genotypes $\mathrm{TA}_{(0)} / \mathrm{TA}_{(0)}$ versus $\mathrm{TA}_{(0)} / \mathrm{TA}_{(9)}+\mathrm{TA}_{(9)} / \mathrm{TA}_{(9)}$.

For each genetic model, the between-study heterogeneities across all of the comparisons were evaluated using the Q-test (Cochran, 1954; Lau et al., 1997). I $^{2}$ statistics was 
also used to estimate the heterogeneity: $\mathrm{I}^{2}$ lies between 0 and $100 \%$, which represents the proportion of heterogeneity across studies rather than chance. Higher values of $\mathrm{I}^{2}$ indicate a greater degree of heterogeneity (Higgins et al., 2003). If the result was $\mathrm{P}<0.05$ or $\mathrm{I}^{2}>50 \%$, heterogeneity was considered significant, and we selected the random-effect model (Mantel and Haenszel, 1959; DerSimonian and Laird, 1986). Otherwise, data were pooled using the fixed-effect model. A sensitivity analysis was performed in order to explore the influence of the studies on the overall OR through sequential omission of individual studies. We also used a funnel plot, which suggests possible publication bias by an asymmetrical plot (Egger et al., 1997; Peters et al., 2006). All P values were two-tailed. To guarantee reliability and accuracy of the results, two reviewers (Q. $\mathrm{Li}$ and $\mathrm{T}$. Yu) independently populated the data using the statistical software programs and received similar results.

\section{RESULTS}

\section{Eligible studies}

Through searching the databases based on the inclusion criteria, only five original articles were eventually included in this meta-analysis. The number of studies with V89L (Yang et al., 2002; van Gils et al., 2003; Francis et al., 2014) and TA repeat data (Bharaj et al., 2000; Spurdle et al., 2001; Yang et al., 2002; Francis et al., 2014) were three and four, respectively. The flow chart of the study selection process is shown in Figure 1. As shown in Table 1, the studies associated with V89L involved 1144 patient and 808 control subjects. The studies associated with the TA repeat included 1952 patient and 1008 control subjects. The publication years of the collected studies ranged from 2000 to 2014. All case subjects were patients with breast cancer. The control subjects were healthy individuals.

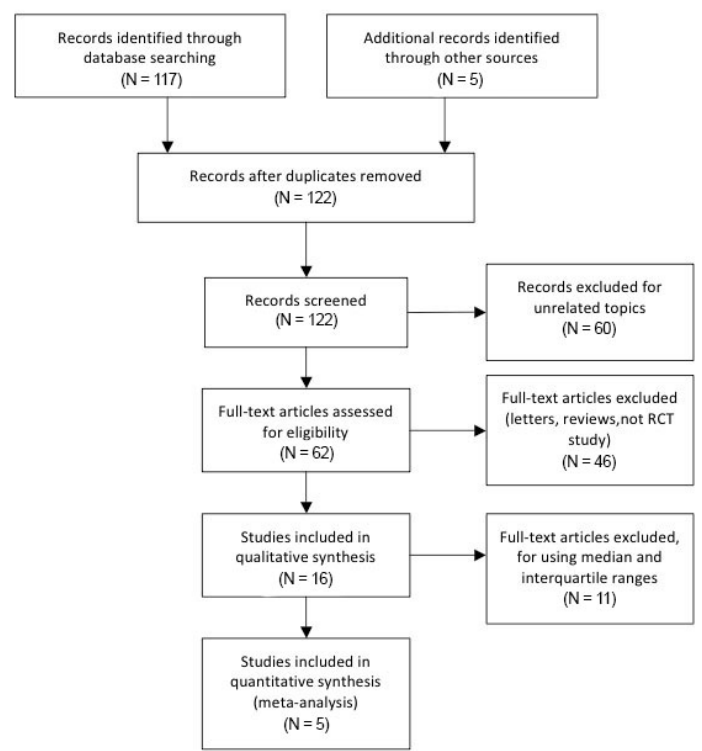

Figure 1. Flow chart on the studies included. In this meta-analysis, 5 studies (studies for V89L genotyping and studies for TA repeat genotyping) were selected for qualitative analysis. 


\section{Quality of the individual studies}

The quality scores of the studies included were all more than five stars. The characteristics and methodological quality of the studies included are shown in Table 1 . The mean value for the studies included was seven stars.

Table 1. Characteristics and methodological quality of the studies included.
\begin{tabular}{llllc}
\hline First author & Year & Number & Method & Quality score \\
\hline Bharaj & 2000 & Breast cancer $(\mathrm{N}=141)$ control $(\mathrm{N}=70)$ & TA repeat & 9 stars \\
Spurdle & 2001 & Breast cancer $(\mathrm{N}=946)$ Control $(\mathrm{N}=409)$ & TA repeat & 7 stars \\
Yang & 2002 & Breast cancer $(\mathrm{N}=237)$ Control $(\mathrm{N}=185)$ & V89L TA repeat & 6 stars \\
van Gils & 2003 & Breast cancer $(\mathrm{N}=295)$ Control $(\mathrm{N}=382)$ & V89L & 8 stars \\
Francis & 2014 & Breast cancer $(\mathrm{N}=628)$ Control $(\mathrm{N}=244)$ & V89L TA repeat & 7 stars \\
\hline
\end{tabular}

\section{Summary of statistics}

In this meta-analysis, the results demonstrated that the V89L and TA repeat polymorphisms of the SRD5A2 gene had no statistically significant association with breast cancer risk. For the V89L polymorphism, the distribution of the L allele showed no prominent difference between patients and controls $(\mathrm{OR}=1.06 ; 95 \% \mathrm{CI}=0.75-1.49 ; \mathrm{P}=0.003$ for heterogeneity; Figure 2). Overall, no significant association between the $S R D 5 A 2$ TA repeat polymorphism and the risk of breast cancer was discovered for the (TA) $)_{0}$ versus $(\mathrm{TA})_{9}$ alleles $(\mathrm{OR}=0.89 ; 95 \% \mathrm{CI}=0.67$ $1.19 ; \mathrm{P}=0.04$ for heterogeneity; Figure 3). In addition, no evidence of an association between the $\mathrm{L} / \mathrm{L}$ genotype and breast cancer relative to the $\mathrm{V} / \mathrm{V}$ genotype was found $(\mathrm{OR}=1.21 ; 95 \% \mathrm{CI}$ $=0.99-1.47 ; \mathrm{P}=0.28$ for heterogeneity; Figure 2$)$. The $(\mathrm{TA})_{9} /(\mathrm{TA})_{9}$ genotype also showed no association with the risk of breast cancer $(\mathrm{OR}=0.91 ; 95 \% \mathrm{CI}=0.66-1.25 ; \mathrm{P}=0.05$ for heterogeneity; Figure 3 ) compared to the (TA) ${ }_{0}(\mathrm{TA})_{0}$ genotype. The significance of the pooled OR in all individual analyses was not influenced excessively by omitting any single study.

\section{V89L polymorphism}
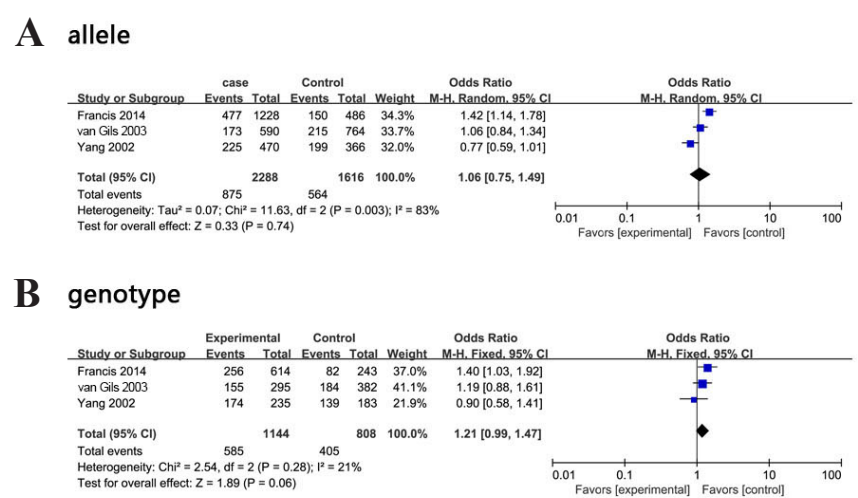

Figure 2. Association between V89L polymorphism of SRD5A2 and breast cancer susceptibility. The size of the squares shows the relative weight of each study. A. Distributions of $\mathrm{V}$ alleles and $\mathrm{L}$ alleles in cases and controls (OR $=1.06 ; 95 \% \mathrm{CI}=0.75-1.49 ; \mathrm{P}=0.003)$. B. Association observed under $\mathrm{L} / \mathrm{L}$ versus $\mathrm{V} / \mathrm{V}$ genotyping contrast $(\mathrm{OR}=$ $1.21 ; 95 \% \mathrm{CI}=0.99-1.47 ; \mathrm{P}=0.28)$. 
TA repeat polymorphism

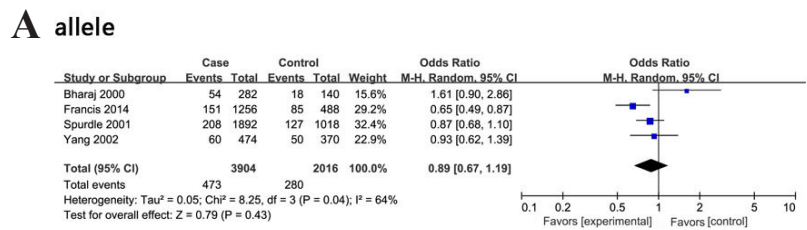

B genotype

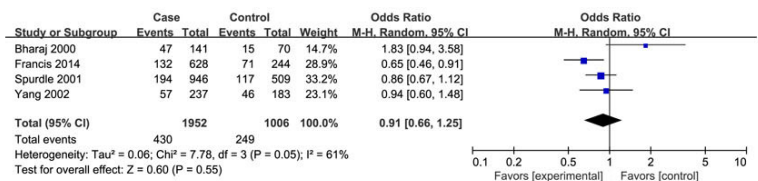

Figure 3. Association between TA repeat polymorphism of $S R D 5 A 2$ and breast cancer susceptibility. The size of the squares shows the relative weight of each study. A. Distributions of (TA) $)_{0}$ alleles and (TA) $)_{9}$ alleles in cases and controls $(\mathrm{OR}=0.89 ; 95 \% \mathrm{CI}=0.67-1.19 ; \mathrm{P}=0.04)$. B. Association observed under $(\mathrm{TA})_{0} /(\mathrm{TA})_{0}$ versus $(\mathrm{TA})_{9} /(\mathrm{TA})_{9}$ genotyping contrast $(\mathrm{OR}=0.91 ; 95 \% \mathrm{CI}=0.66-1.25 ; \mathrm{P}=0.05)$.

\section{Sensitivity analysis}

According to the quality of the studies included, sensitivity analysis was performed in this meta-analysis. We selected relatively high-quality studies ( $\geq 7$ stars) for the analysis. As shown in Figure 4, we obtained the result that the TA repeat polymorphism variants of the SRD5A2 gene had no correlation with breast cancer susceptibility (TA allele: $\mathrm{OR}=0.90$; $95 \% \mathrm{CI}=0.61-1.32 ; \mathrm{P}=0.02$ and TA genotype: $\mathrm{OR}=0.92 ; 95 \% \mathrm{CI}=0.60-1.41 ; \mathrm{P}=0.02)$. The result of the sensitivity analysis was consistent with the previous result, which demonstrated that the TA repeat had no association with the risk of breast cancer.

A TA repeat polymorphism

allele

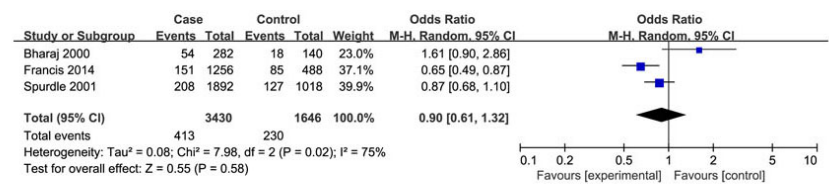

B genotype

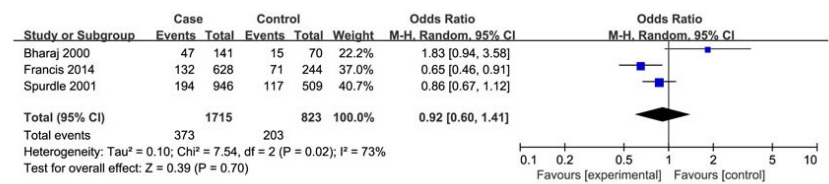

Figure 4. Sensitivity analysis. The relatively high-quality studies (stars $\geq 7$ ) were selected from the sensitivity analysis. A. Distributions of (TA) $)_{0}$ alleles and (TA) $)_{9}$ alleles in cases and controls $(\mathrm{OR}=0.90 ; 95 \% \mathrm{CI}=0.61-1.32$; $\mathrm{P}=0.02)$. B. Association observed under $(\mathrm{TA})_{0} /(\mathrm{TA})_{0}$ versus $(\mathrm{TA})_{9} /(\mathrm{TA})_{9}$ genotyping contrast $(\mathrm{OR}=0.92 ; 95 \% \mathrm{CI}$ $=0.60-1.41 ; \mathrm{P}=0.02)$. 


\section{Publication bias}

The publication bias was examined by a funnel plot across various comparative models for both V89L and TA repeat polymorphisms of the SRD5A2 gene. The graphical funnel plots of the included publications were symmetrical (Figure 5), suggesting that there were no evidence of publication biases among the studies included in this analysis

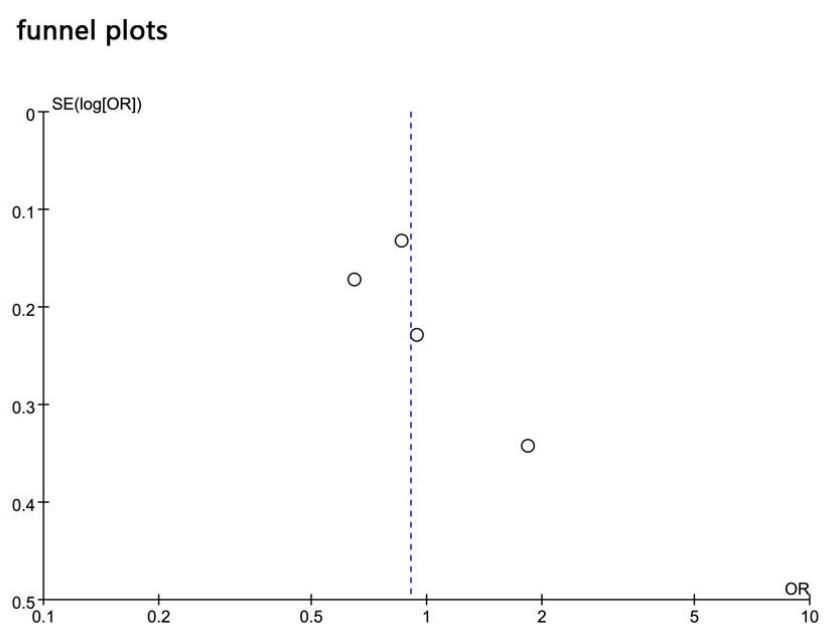

Figure 5. Graphical funnel plots of the studies included. These symmetrical plots indicate the absence of publication bias in the present meta-analysis.

\section{DISCUSSION}

Breast cancer has been considered a hormone-associated malignancy that is tightly correlated with estrogen levels. Evidence has indicated that P metabolites had an important impact on regulating breast cancer (Wiebe et al., 2000). Analysis of P metabolism has identified 5 $\alpha$-reductase as one of the most important P-metabolizing enzymes in human mammary gland tissues, through catalysis of the conversion of $\mathrm{P}$ to $5 \alpha \mathrm{P}$ (Wiebe, 2006). Production of $5 \alpha \mathrm{P}$ occurs at a higher rate in tumorous than in nontumorous human breast tissue. Additionally, the $5 \alpha$-reductase reduction is irreversible in breast cancer (Wiebe et al., 2006). The $5 \alpha$-reductase enzyme has two isoforms: types 1 and 2 (Wigley et al., 1994). SRD5A2 encodes the steroid 5 $\alpha$-reductase-type 2 enzyme, which is expressed primarily in the prostate and breast glands. Estrogens have been shown to be the main risk factors in the development of breast cancer (Krajinovic et al., 2001; Yager and Davidson, 2006). Thus, SRD5A2 polymorphisms are thought to likely be significant in the etiology of breast cancer. The common genotype polymorphisms of SRD5A2 are the V89L missense substitution and the TA repeat. Our meta-analysis investigated the relationship between these two well-characterized variations of the SRD5A2 gene and breast cancer susceptibility.

In the current literature, no definitive conclusion on the association between the V89L polymorphism of the SRD5A2 gene and breast cancer risk has been reached, as the respective correlations have been inconsistent. One study found that there was no evidence for a significant role of the V89L variation in the risk of breast cancer (van Gils et al., 2003); how- 
ever, conflicting results also had been detected. Francis et al. (2014) reported that genotype comparisons demonstrated that patients carrying the $\mathrm{L} / \mathrm{L}$ genotype were at significantly higher risk of breast cancer than those with $\mathrm{V} / \mathrm{L}$ and $\mathrm{L} / \mathrm{L}$. However, another report had discovered the opposite result, wherein the V89L L/L genotype was associated with a decreased risk of breast cancer, compared with V/V (Yang et al., 2002). In order to examine the true association of this variant with breast cancer risk, a meta-analysis of 3 studies containing 1144 patients and 808 controls was carried out. The result indicated that no significant difference in the distribution of V89L genotypes between patients and controls could be identified. Therefore, statistically the V89L polymorphism does not appear to have an important association with breast cancer risk.

Similar to the V89L polymorphism of the SRD5A2 gene, a few studies have generated some relevant data about the relationship between the TA repeat variants and breast cancer risk, but the results are also controversial. Some studies have claimed that a markedly increased risk of breast cancer was associated with the (TA) ${ }_{0} /(\mathrm{TA})_{0}$ genotype, and that the $(\mathrm{TA})_{0} /$ $(\mathrm{TA})_{9}$ or $(\mathrm{TA})_{9} /(\mathrm{TA})_{9}$ genotypes were more common in controls (Francis et al., 2014). Yang et al. (2002) found that the (TA $)_{0} /(\mathrm{TA})_{9}$ genotype decreased the risk of breast cancer. However, studies have also obtained different results. In a small study with 141 patients and 70 controls from Italy, the result showed that there was no significant relationship between the TA repeat polymorphism and breast cancer risk (Bharaj et al., 2000). A similar result was found in Australian women (Spurdle et al., 2001). We included four relevant studies on the relationship between TA repeat variations and the breast cancer risk. In total, 1952 patients and 1008 controls were included. By our analysis, there was no indication that the TA repeat polymorphism had any significant association with the risk of breast cancer.

Even though the SRD5A2 is a critical enzyme in estrogen metabolism, and even though the recognized polymorphisms modulate its activity under certain circumstances (Davis and Russell, 1993), no conclusive evidence has indicated that the levels of hormone have an effect on the risk of breast cancer. Thus, the relationship betwen the polymorphisms of $S R D 5 A 2$ gene and breast cancer should be validated carefully by abundant studies. However, the number of correlated articles was small in this meta-analysis, which is its main limitation. In addition, some published studies included a small sample size. For this complex disease with multi-genetic associations, large sample sizes are required to examine the relationship between the V89L and TA repeat polymorphisms of the SRD5A2 gene and breast cancer susceptibility. Certain other limitations of our meta-analysis also need to be acknowledged. First, some high-quality studies were excluded owing to a lack of raw data (Scorilas et al., 2001). Furthermore, the studies could not exclude latent breast cancer in the controls, who might have had different risks for developing breast cancer. Third, the patients and controls of the studies were determined by similar inclusion criteria; however, certain potential factors were not considered, which might have affected the results (age, smoking status, ethnicity, etc.). Thus, our conclusions should be interpreted cautiously, and a more accurate analysis needs to be performed when enough data become available.

In summary, this meta-analysis demonstrated that the V89L and TA repeat polymorphisms of the SRD5A2 gene have no significant associations with the risk of breast cancer. Owing to the limitation of the number of published studies in this field, and their sample sizes, a greater number of studies with adequate numbers of patients and controls should be taken into account in future research to accurately understand the underlying association of SRD $5 A 2$ variation with breast cancer risk. 


\section{REFERENCES}

Althuis MD, Dozier JM, Anderson WF, Devesa SS, et al. (2005). Global trends in breast cancer incidence and mortality 1973-1997. Int. J. Epidemiol. 34: 405-412.

Bharaj B, Scorilas A, Giai M and Diamandis EP (2000). TA repeat polymorphism of the $5 \alpha$-reductase gene and breast cancer. Cancer Epidemiol. Biomarkers Prev. 9: 387-393.

Cochran WG (1954). The combination of estimates from different experiments. Biometrics 10: 101-129.

Davis DL and Russell DW (1993). Unusual length polymorphism in human steroid 5 $\alpha$-reductase type 2 gene (SRD5A2). Hum. Mol. Genet. 2: 820.

DerSimonian R and Laird N (1986). Meta-analysis in clinical trials. Control. Clin. Trials 7: 177-188.

Egger M, Davey Smith G, Schneider M and Minder C (1997). Bias in meta-analysis detected by a simple, graphical test. BMJ 315: 629-634.

Francis A, Sarkar S, Pooja S, Surekha D, et al. (2014). SRD5A2 gene polymorphisms affect the risk of breast cancer. Breast 23: 137-141.

Higgins JP, Thompson SG, Deeks JJ and Altman DG (2003). Measuring inconsistency in meta-analyses. BMJ 327: 557-560.

Krajinovic M, Ghadirian P, Richer C, Sinnett H, et al. (2001). Genetic susceptibility to breast cancer in French-Canadians: Role of carcinogen-metabolizing enzymes and gene-environment interactions. Int. J. Cancer 92: 220-225.

Lau J, Ioannidis JP and Schmid CH (1997). Quantitative synthesis in systematic reviews. Ann. Intern. Med. 127: 820-826.

Leclercq $G$ and Jacquot $Y$ (2014). Interactions of isoflavones and other plant derived estrogens with estrogen receptors for prevention and treatment of breast cancer-considerations concerning related efficacy and safety. J. Steroid Biochem. Mol. Biol. 139: 237-244.

Lewis MJ, Wiebe JP and Heathcote JG (2004). Expression of progesterone metabolizing enzyme genes (AKRICl, $A K R 1 C 2, A K R 1 C 3, S R D 5 A 1, S R D 5 A 2)$ is altered in human breast carcinoma. BMC Cancer 4: 27.

Mantel N and Haenszel W (1959). Statistical aspects of the analysis of data from retrospective studies of disease. J. Natl. Cancer Inst. 22: 719-48.

Peters JL, Sutton AJ, Jones DR, Abrams KR, et al. (2006). Comparison of two methods to detect publication bias in metaanalysis. JAMA 295: 676-680.

Reding KW, Li CI, Weiss NS, Carlson CS, et al. (2009). Genetic variation in the progesterone receptor and metabolism pathways and hormone therapy in relation to breast cancer risk. Am. J. Epidemiol. 170: 1241-1249.

Sang LX, Chang B, Li XH and Jiang M (2013). Consumption of coffee associated with reduced risk of liver cancer: a meta-analysis. BMC Gastroenterol. 13: 34.

Scorilas A, Bharaj B, Giai M, Diamandis EP, et al. (2001). Codon 89 polymorphism in the human $5 \alpha$-reductase gene in primary breast cancer. Br. J. Cancer 84 : 760-767.

Spurdle AB, Hopper JL, Chen X, Dite GS, et al. (2001). The steroid $5 \alpha$-reductase type II TA repeat polymorphism is not associated with risk of breast or ovarian cancer in Australian women. Cancer Epidemiol. Biomarkers Prev. 10: 1287-1293.

Tian C, Liu L, Yang X, Wu H, et al. (2014). The Val158Met polymorphism in the COMT gene is associated with increased cancer risks in Chinese population. Tumor Biol. 35: 3003-3008.

van Gils CH, Onland-Moret NC, Roest M, van Noord PA, et al. (2003). The V89L polymorphism in the $5 \alpha$-reductase type 2 gene and risk of breast cancer. Cancer Epidemiol. Biomarkers Prev. 12: 1194-1199.

Wiebe JP (2006). Progesterone metabolites in breast cancer. Endocr. Relat. Cancer 13: 717-738.

Wiebe JP, Muzia D, Hu J, Hill SA, et al. (2000). The 4-pregnene and 5 $\alpha$-pregnane progesterone metabolites formed in nontumorous and tumorous breast tissue have opposite effects on breast cell proliferation and adhesion. Cancer Res. 60: 936-943.

Wiebe JP, Souter L and Zhang G (2006). Dutasteride affects progesterone metabolizing enzyme activity/expression in human breast cell lines resulting in suppression of cell proliferation and detachment. J. Steroid Biochem. Mol. Biol. 100: 129-140.

Wigley WC, Prihoda JS, Mowszowicz I, Mendonca BB, et al. (1994). Natural mutagenesis study of the human steroid 5. alpha.-reductase 2 isoenzyme. Biochemistry 33: 1265-1270.

Yager JD and Davidson NE (2006). Estrogen carcinogenesis in breast cancer. New Engl. J. Med. 354: 270-282.

Yang C, Hamajima N, Iwata H, Saito T, et al. (2002). A49T, V89L and TA repeat polymorphisms of steroid 5alphareductase type II and breast cancer risk in Japanese women. Breast Cancer Res. 4: R8.

Yip CH and Taib NA (2014). Breast health in developing countries. Climacteric 17: 54-59. 